\title{
The subjective view of life "evenness of mind is yoga. Equanimity within is spiritual life" (Gita: 2-48)
}

\begin{abstract}
This Paper looks at a particular aspect of human nature known as difference, the difference that separates us from each other due to the divisions and boundaries created by cultural, linguistic and religious gaps. It is my intention within this Paper to explore these areas of difference between east and west and to go beyond conventional psychology to the spiritual plane, which is one of the greatest mysteries of the universe. It is my experience that within psychology it manifests at the microcosmic level between a therapist and a client when differences of culture, language, philosophy and religion are not acknowledged and recognised. Spiritual issues and problems normally arise in psychotherapy practice and very few therapists are equipped to work with them. Eastern methods of Yoga and meditation are invaluable in deepening a therapist's own spiritual exploration, which demands very intense and high standards of discipline and training and is essential for fostering transpersonal growth. By integrating Yoga in therapy, which literally means "Joining" (body, mind and soul), a holistic method of healing (therapy) can be created to overcome existing hurdles in current psychotherapy. We can only help others transform when we have transformed that within ourselves.
\end{abstract}

Keywords: yoga, spiritual life, psychotherapy, humanity, mystic union
Volume 2 Issue 3 - 2017

Meera Sharma
Director of Centre for Spiritual and Transpersonal Studies, UK

Correspondence: Meera Sharma, Director of Centre for Spiritual and Transpersonal Studies, UK, Tel +440 208578 333I, Email msharma669@aol.com

Received: May 19, 2017 | Published: August 04, 2017

\section{Introduction}

It seems that while integrating eastern spiritual dimensions into modern psychology, greater emphasis has been placed on psychology and very little importance is placed on the awareness of spirituality. In my view, perhaps transpersonal psychology and psychotherapy need to address the broadest conceptualisation possible for human psychological growth. This includes, along with comfort and gratification in one's relationship with self, family, work and society, recognition of the yearning for meaning, purpose and transcendence of self-consciousness as part of our nature. It appears that transpersonal psychology and psychotherapy presuppose the existence of a spiritual dimension in human beings and being a transpersonal therapist presupposes sharing this conviction. Although the field is not limited to any particular systems, spiritual or religious, it appears to recognize just the validity of spiritual systems in general and not the yearning for spiritual unfolding as one of the givens of human growth and development.

Yoga is another word that has become very popular in the west, but it is totally misunderstood and abused without any hesitation. It is used commonly and loosely and practised as any physical exercise without any purposeful knowledge, depth or understanding. It is very sad to observe this happening; it is like eating the peel and throwing the fruit away. A lack of meaningful understanding of language and culture could be one of the main reasons behind this.

It appears that most of us are trying to live a deeper and meaningful life, but moving nowhere because of not applying proper principles for integration and transformation. Yoga Psychology reveals how we can reach this by simple and easy steps. Yoga in Psychology answers all questions of our body, emotions, feelings, thoughts, dreams, desires, nature and our true purpose in life. Most of us are living a onedimensional life and yoga psychology takes us to a multidimensional life of fulfilment and meaning.
Yoga Psychology is not a philosophy; it is a science for the welfare of humanity. It helps us to a better understanding of our body, mind and spirit and leads us towards complete fulfilment of a meaningful life. It is an ancient wisdom revealing how we can master our various dimensions of consciousness to transform us from suffering to freedom. It is a science about changing our lives towards complete fullness.

According to Swami Ghanananda, "Yoga is a science. It is applied psychology". Yoga is the most practical school of Indian philosophy. The word Yoga is derived from the Sanskrit root yuj, which means "to unite". It is the Sanskrit ancestor of the English word "yoke". Hence, it comes to mean a method of spiritual union. To achieve such union is to reach the state of perfect Yoga. Christianity has a corresponding term, the "mystic union", which expresses a similar idea. The Yoga system provides a methodology for expanding one's individual consciousness to universal consciousness. There are various schools of Yoga, for example: Bhakti Yoga, Jnāna Yoga, Karma Yoga and Kundalini Yoga. It is quite a deep and vast subject and it would not be possible or practical to discuss all these various approaches to Yoga here. I will, therefore, focus on the one most comprehensive approach known as the Patanjali Yoga Sutra.

Patanjali was the first sage to systematise the philosophy and practice of Yoga. There are various commentaries on this text; Vyāsa's being the most ancient and profound. Bhoja (1957: p1), one of the classical commentators, defines Patanjali use of the word Yoga as "an effort to separate the Atman (the Reality) from the non-Atman (the apparent)". One who practises Yoga is called a Yogi. The philosophical approach to Yoga psychology is grounded in the teaching of Samkhya philosophy, Patanjali's Yoga Sutras, the Upanishads and other sacred texts. This perspective takes into account that we are a meaningmaking species. This philosophical approach enables us to find hope in the face of tragedy. The simple act of meaning-making can turn 
a horrendous tragedy into an opportunity to learn how to tolerate difficult emotions, improve existing relationships and begin to connect with other nourishing relationships that surround us. ${ }^{2}$

The modifications of the mind $^{3}$ are caused by impediments, namely: sickness, incompetence, doubt, delusion and confusion. These impediments disturb the mind and produce sorrow, restlessness and a non-rhythmic breathing pattern. Yoga provides a method for overcoming these problems and controlling the modifications of the mind. Patanjali states that the mind and its modifications can be controlled through practice (abhyăsa) and detachment (vairăgya) Abhyăsa (or practice) means a particular type of effort or technique through which the mind maintains stillness. Perfection in practice is attained through sincerity and persistence. On the other hand, Vairăgya (or detachment) here does not mean withdrawing oneself from one's environment; rather it means to have no expectations from external world objects. Detachment means to eliminate identification with nature and to understand oneself as pure self, as a self-illuminating conscious being.

According to Patanjali Yoga the eightfold paths (also known as Astānga Yoga) have the necessary qualities and conditions for reaching the subtler levels of consciousness, which eventually lead to realisation of the highest state of consciousness. We all have access to this state of consciousness, regardless of any emotional problems we may have. In my experience, this state of consciousness does not "fix" mental illness, but it does open us to experience the totality of our being. We begin to see ourselves from a higher perspective. We may see, "Oh yes, my mind is prone to anxiety and has difficulty feeling safe," but we also experience that we are so much more than the body and mind. We experience that our mental suffering is temporary, while our soul is eternal. We see quite clearly that our mental afflictions are a path that, if followed, will lead us to develop wisdom, compassion and love. It helps my clients in reducing their anxiety when I say to them that "you have a problem but you are not a problem".

Higher states of consciousness evoked by Yoga have the unique effect of settling the mind, because we are no longer wrestling with "mental illness". We no longer push it aside as something unworthy of our attention, or as a bother. We begin to accept the eating disorder, the traumas, the anxiety and the difficulties connecting with others as functional adaptations to extremely traumatic situations. We begin to see the limitations of these strategies and can consciously choose to replace them with yogic tools that help to keep us safe in ways that are not harmful to us. We begin to accept that we have to engage in self-care if we are truly to begin healing and recover our sense of self

\section{Applications of yoga in psychology}

There is often a prescriptive approach in Yoga Psychology for specific psychological effects. For example, if someone suffers from anxiety, the Yoga therapist may assign them a specific series of restorative Yoga poses and breathing practices. This approach is incredibly valuable as a way to begin the individual's commitment to the important role of discipline in healing. This practical perspective is imperative to the success of Yoga in Psychology, but reifies the idea that we are solely our bodies; that if we manipulate the body in the "right way" we will find peace and happiness.

The practices of Yoga help us to regulate our energy level. If our energy level is too low (a tamasic, hypo-aroused state in which we feel dull, heavy, lethargic and tend to dissociate), we may engage in a slightly vigorous posture-based practice. If our energy level is too high (a rajasic, hyper-aroused state in which we feel anger, anxiety, tension and racing thoughts), we may engage in a slow or restorative posture-based practice. Over time, we begin to learn how uniquely to adapt Yoga asanas, pranayama, meditation, yogic diet, chanting, selfstudy and exploration of the philosophical texts in ways that help us relate to our emotional states. Concurrent with the above findings, it appears that spirituality runs as an undercurrent through philosophy, religion, culture, language and psychology.

The relationships between psychotherapy and eastern spiritual practices, such as meditation and yoga, have been repeatedly questioned. It can be argued that the task of psychotherapy is to expand a person's awareness of who he/she is by integrating the parts of himself/herself that he/she so far has disowned. Psychotherapy has different levels and functions to it, depending on the goals and the understanding of the client and therapist. One can say it is an effective way of solving life's problems and of developing a functional sense of self. It can also help people deepen feelings and their sense of an inner life. In some cases, it may even help people begin to break through the protective shell that surrounds the heart, thus enabling them to be more receptive and open to the world around them and be able to meet others more fully. In short, it is a process of sorting out confusion and self-integration, but not self-transcendence. Perhaps it enables the expansion of one's "I" sense, but not dissolve it.

The nature of eastern and western spirituality appears to be quite consistent with current psychotherapy practices. Separating both psychotherapy and spirituality can be beneficial in the sense that it can help prevent dangers and distortions caused by differences and misunderstandings. But in essence both do co-exist and in-depth psychology does become spirituality. It might be argued that love, compassion, respect and acceptance are vital qualities for growth and healing. It seems to me no amount of clinical training or theoretical study is going to help my clients unless I experience these qualities for myself, for, as Ram Dass ${ }^{4}$ says, what one person has to offer to another is their own being, nothing more, nothing less.

My fascination with transpersonal psychology proved to be disappointing, to some extent, as I realised that these authors have drawn their ideas from particular religious approaches. It is my contention that most people in the west understand spirituality from a religious perspective. As I understand it, religions preach unconditional love, but do not necessarily practise it. Religious people seem to be too attached to their belief systems and this attachment brings insecurity. I suppose this may well be the case with different psychological approaches to psychotherapy as well. Sometimes therapists become over-identified with their particular model or approach to psychology and find it hard to walk their talk. While living a conflicting life themselves, it can be difficult to guide clients to live up to their convictions. This is the dilemma that I feel has become an epidemic in current psychotherapy culture. It would appear to be consistent with previous findings that insecurity comes from attachment and lack of trust and out of fear of insecurity develops "difference", which further creates feelings of isolation, exclusion and separateness. I suppose this must be the reason that all spiritual traditions of the world teach us not to be so attached and to develop love. Love is the opposite of attachment, but only traditional psychology does not talk much about love. I wonder if there is an element of attachment to structure, boundaries and differences within current psychology culture, which may be primary to its existence in its present form. It appears that if 
one looks at the growing amount of modern research conducted in this area (by writers such as Almas, Grof, Wilber and so forth), it is becoming more and more evident that ancient spiritual traditions developed effective means of overcoming such barriers to human growth, mostly through self-reflection of "Who am I?"

My idea of introducing eastern spirituality into psychology is to have a deeper understanding of human nature and bring about quality to life, instead of counting the number of approaches available. I believe by linking language, culture and current psychotherapy to these spiritual traditions a bridge can be formed over this gap between essence and personality and one can learn to communicate at higher levels of frequencies without causing distortion to either language or culture.

Currently, an eastern orientation is becoming increasingly important in the west, as the realisation comes that there is more to life than western philosophy suggests. The search for and love of, knowledge are intrinsic to human nature. The modern western approach addresses the problem from an objective, theoretical and pluralistic standpoint, whereas the ancient eastern approach is more subjective, experiential and holistic. The west looks outward to external data and the east turns inward to internal experience; one method is based primarily on dialectics and discursive deductive speculation, while the other is based on introspection and direct intuitive insight. In the western concept, man is a body with a soul, whereas all eastern systems consider him to be a soul with a body. Perhaps as a result of this view, in the west the dead body is buried to preserve it as long as possible, while in the east it is burned to release the soul as early as possible.

As the west is becoming increasingly interested in the subtle aspects of reality, the basic assumptions of both philosophies are becoming less and less divergent. Modern western science is now beginning to come to the same conclusions as the Vedantic philosophy of all-pervading consciousness. Quantum field theory and the theory of relativity are pointing towards the essential unity of all things. The disciplines of physics and metaphysics are also finding common ground. The western world is in search of an intellectually satisfying explanation of the nature of reality in exploring the wisdom of the eastern worldview. This transition from materialism to idealism is clearly evident in modern art, culture and literature. Western psychology has also been actively engaged in an exploration into the nature of reality. New branches of psychology have emerged to find solutions to the mental problems on deeper levels, such as transpersonal psychology, the psychology of consciousness and parapsychology, which investigates subtleties of life beyond mind. To understand what truth is, more and more westerners are investigating the eastern approach as well as the western approach. Psychotherapy, however (being limited by professional and monetary constraints) is unable to integrate such high levels of spiritual understanding. A psychotherapist, who has no such background of deep philosophical understanding of the spiritual nature of eastern culture and language, can run the risk of confusing the two. The eastern teachings assume that a person already has a healthy self-structure. But under modern society's crumbling family structures, traditional and community systems, these assumptions are under threat and are challenged.

It seems that the totally unfamiliar nature of eastern philosophy could be quite perplexing for a western scholar who is trying to study this different orientation. This is understandable because only a few western philosophers, such as Plato, Augustine and Berkeley, have come close to such idealistic frameworks as found in eastern philosophy. Perhaps it is the immense depth and vastness of Vedantic knowledge that is feared by the west, which likes to feel safe within structure. It appears that some westerners interested in Buddhism find it more approachable because they are attracted to its richness in the realms of logical reasoning and meditation. They find Buddhism safe due to its logical structure, which is very much in line with western ways of thinking and their extrovert attitude.

Language is also the most important tool that describes us as human. Looked at from many different aspects, mainly the esoteric and western linguistic understanding of language is of real importance here. Esoteric language means the language that describes metaphysical reality and enables the seeker to experience transformative processes. Letters as metaphors of reality have no transcendental external meaning-their meaning is in the minds of those who have learnt them. The esoteric aspect of the scripture is of a secret nature couched in mystical language and understood only by a few initiates who actually practise the teachings and attain the highest benefit from them. Alternatively, scriptures are communicated in some cultures through metaphorical stories-myths and legends. In their esoteric or metaphysical aspects, they can convey meanings that cannot be expressed adequately by any other means. They are symbols that can express non-verbal experiences that can alter one's consciousness drastically.

The very basis of language is metaphorical and symbolic, as it represents objects and concepts, while it is not these objects and concepts themselves. Wallwork ${ }^{5}$ stresses the symbolic nature of language and clearly suggests that when we use our symbols differently, it gives rise to confusion. It is evident from current research and studies how our understanding of culture, philosophy and symbols changes the meaning of words. One often wonders if the teachings of old scriptures are the message that Christ or Buddha were trying to convey to us or is it just a compromise; for example, their understanding that language can convey so many different meanings at different levels, dependent on the recipient's ability to internalise? I often find it difficult to express my thoughts and feelings in any language. Even when I manage to do so, others do not understand them as I have experienced them.

Culture has a deep impact on language. Language is also an expression of culture and vice versa; they overlap each other. They both play a most important and active role in the evolution of human development. Culture is socially transmitted and profoundly affects our ways of thinking about and seeing the world around us, understanding relationships among people and things and events. It seems that we understand only culturally the meaning of language. In order for there to be a truly richer, holistic understanding of eastern language, culture and philosophy, we need to acknowledge the difference in language, culture and philosophy, otherwise there will only be a superficial understanding of what the east has to offer in terms of reflectiveness and depth. It appears to me that the lack of understanding of a particular language and culture could be one of the major reasons for getting translations from eastern scriptures wrong. For example, the "supermarket attitude" of the west: in supermarkets people pick up packets of food just by reading the label. They have little idea how it got to the shelf and what it is going to do to them.

I feel this is truly an exceptional time in the history of humankind, which calls for exceptional changes to take place. Instead of dreaming, we can wake up to the reality of "universal culture". Thus it appears 
that the relationship between language, thought and experience is one of great complexity, with the implication being that both thought and experience are dominated and limited by language. And, specifically, when learning about another culture the limitations of language in the translation of meaning are clearly highlighted. For example, in the Sanskrit language there are many words for "one thing' sun, moon, water, air, fire, even river and ocean-everything has at least 30 to 50 different names or may be more. They were created to fit into one's inner reality. The word prabhāt means rising, innocent, baby-like sun that is just emerging from the dark womb of the night. It is associated with new beginnings, more so as it has spiritual associations with the meaning of awakening and light of consciousness rising in one's inner horizon, a time for salutation to one's eternal nature. This word prabhat is only meant for the moment the sun rises; it cannot be used for midday or noon sun. There are different names for the sun for other timings. There is a word for "sunrise" (suryodyā) that is understood more in theoretical terms. But prabhāt has a more experiential, spiritual and phenomenological sense to it. It is changeable and different from one day to another. Like in the English language the word 'dawn' is for the rising sun; that is the sun of the day. But prabhät contains in it the energy of the uniqueness of that moment as its capacity of creation of cosmic light, a birthing time, a new beginning. It is not the sun of the day; the sun is different at different times of the day. But somehow these words appear to give a sense of external surface and correspond with the extrovert nature of the west.

While exploring the changed meaning of Sanskrit words, it was evident to me how deeply we, as human beings, are rooted in our inherent culture and language, when we relate to our mother tongue, our cognition, emotions, sensation changes, along with our perception and consciousness. This shift in consciousness changes the meaning and our understanding of that object; the subtleness of this unique experience can only be realised and cannot be described. Perhaps it is that when we penetrate the depth of our own reality (which is our true nature), we are able to energise it, evoke the fire to bring light and warmth into our being. This is the most empowering internal experience, which does not take the outside world into consideration. It is so enriching that outside temptations are powerless; it is like when you have had a good, satisfying meal you can go past a most posh restaurant without even glancing at what is being served there. But in modern society, circumstances and pressures are such that we cannot always depend on home cooking. At times we need to get a "take-away" or go to a restaurant to eat. That means we need to get back to the surface from the depths from time to time to know what else is available to us. Remaining in the depths for too long could also cause resistance towards touching the surface. As westerners have a resistance for going into eastern Vedantic depths and try to satisfy themselves by alternative means (which do not actually serve the purpose of fulfilment of their need to realise their full potentials), similarly the east, completely absorbed in its inner depths, has faced difficulties in developing its external potential. So, despite possessing great knowledge and wisdom, she still falls into the third-world country category. We need to aim for a balance; it may be hard to maintain the continuity of such balance, but once this optimum point is reached, we will have the confidence to regain it.

The same is in the case of meditation and Yoga; much has been lost by not going into the depth of these eastern traditions. These practices are totally experiential, beyond the realms of mind. The fear to go into such a vast ocean of experience is understandable. It is like being thrown into the ocean when you do not know how to swim. Perhaps some swimming training and understanding of the depth of the ocean could reduce the fear and might result in a more relaxing experience. Even the ocean can be tamed to some extent where it does not appear to be so frightening. Once you have been to the depth and come back to the surface, you get a clearer picture of what lies below. The surface can be appreciated and the depth not feared any more. The east is the depth and the west is the surface. The alchemical process of growth (prima materia) also talks about this chaotic stage through which creativity brings order. Transforming matter (Akash a mixture of everything) by bringing the spirit into the matter is what is important. We have to take risks and experiment in order to find suitable grounds for this bridge over eastern and western differences to be created. All I know is that it is possible; we may not get what we want, but we certainly can have what we need.

It also means that changing the meaning of words can also change the meaning of two different worlds and unify them. It may not be the desired colour of black and white and we may end up with a grey colour, but is that not what all this chaos is about? Unity- VasudhaivKutumbakam-the whole world is but one family.

\section{Conclusion}

In conclusion, it can be seen that we still have a long way to go. My suggestion for future development will be to adopt the means to reduce these differences. Our differences make us interesting and they can be very enriching if only we allow them to be. Counselling/ psychotherapy therefore demands a diverse approach, ${ }^{6}$ which means valuing differences and treating people in ways which bring out the best in them.

Living in a multicultural society has not changed us much in our attitude towards each other. It is important to have openness and acceptance of each other's cultural differences. We must overcome this fear of difference and develop love, respect and understanding for each other. These are the weapons to conquer the war of "Universal Unity". A spiritual awakening within humanity is of supreme importance to wake people up to their inner reality and enable them to trust themselves enough to be able to trust others. We have not yet learned how to respect each other fully, how to share and work together. The world as we know it and all the relationships we took as given, are undergoing profound rethinking and reconstruction. Imagination, innovation, vision and creativity are required. International partnerships and interaction is an essential ingredient for creativity in problem solving, a quality that requires willingness to frame-hold questions instead of depending on conventional answers. It means an open mind, an open heart and a readiness to seek fresh definitions, reconcile old opposites and help draw new mental maps. Ultimately, it will be the honesty of introspection that will lead to compassion for the other's experience and it will be compassion that will lead us to a future in which the pursuit of individual freedom will be balanced with a need for common well-being and in which our agenda will include empathy and respect for the entire spectrum of human difference.

The experience of Yoga is quite different from understanding Yoga. Spiritual experiences are not ideas; they are quite literally experiences. They give us the felt and embodied sense of humility, empowerment, trust, order, the ability to stay grounded despite the natural flux and change of the world and the skill to discern the complexities that exist behind simplistic categories of right and wrong. The spiritual component of Yoga is what will ultimately transform us in profound 
and unexpected ways. Through living the practices of Yoga we come into direct contact with joy, contentment, love and compassion. Our culture is slowly realizing that these are significant qualities, worth developing. Regardless of whether one lives in the east or west, a human being is a human being first and a real human being is a member of the cosmos.

\section{Acknowledgements}

I would like to thank and acknowledge the support of Dr Joseph Ryan for his valuable suggestions and careful editing in the preparation of this paper.

\section{Conflicts of interest}

I, the author of this above manuscript, certify that I have NO affiliations with or involvement in any organization or entity with any financial interest (such as honoraria; educational grants; participation in speakers bureaus; stock ownership or other equity interest) or non-financial interest (such as personal or professional relationships, affiliations, knowledge or beliefs) in the subject matter or materials discussed in this manuscript. ${ }^{7-26}$

\section{References}

1. Ghanananda S. Meditation, Monks of the Ramakrishna Order. UK Ramakrishna Vedanta Centre; 1972.

2. Prabhavananda S. Patanjalis Yoga Sutras. India: Sri Ramakrishna Math; 1957.

3. Rajmani TP. Seven systems of Indian philosophy. India: Himalayan Institute Press; 1983. 261 p.

4. Walsh RN, Vaughan F. Paths beyond ego. USA: Tarcher Putman; 1993.

5. Wallwork JF. Language and linguistics. India: Heinemann Educational Books; 1989.

6. Ansari, Jackson J. Managing Culture: Diversity at Work. Kogan, UK: HR in Asia; $1995.11 \mathrm{p}$.

7. Balasubramanian R. Primal spirituality of the Vedas. India: Primal spirituality of the Vedas; 1996. 240 p.
8. Bodhananda S. Meditation: The awakening of inner powers. India: Surya Print Process; 1995. 156 p.

9. Bram RW. Language and categories. In: Bruner JS, editor. A study in thinking. USA: Wiley; 1956.

10. Brown DJ. Masks of mystery: Explorations in Christian faith \& arts. USA: University Press of America; 1996.

11. Green B. Consideration in the treatment of black patients by white therapists. Psychotherapy. 1985;22(2):389-393.

12. Griegor I, Ponterotto J. A framework for assessment in multicultural counselling. Ponterotto J, et al. editors. Handbook of multicultural counselling. Sage, UK: 1995. p. 357-374.

13. Hall ET. Beyond culture. USA: Anchor Press; 1976. 281 p.

14. Hiriyanna M. Essentials of Indian philosophy. UK: Allen \& Unwin; 1949. $218 \mathrm{p}$.

15. Lago C. Race, culture and counselling. UK: Open University Press; 1996. $168 \mathrm{p}$.

16. Paddison S. The hidden power of the heart. USA: Planetary Publications; 1995.

17. Pennick N. Magical alphabets. USA: Samuel Weiser Inc; 1995.300 p.

18. Popper K. Objective knowledge. Hacking I, editor. Why does language matter to philosophy? USA: Cambridge University Press 1975.

19. Sheldrake P. Spirituality and history. USA: Spectrum; 1991.

20. Sue D, Sue D. Counselling the culturally different: Theory and practice. USA: Wiley; 1990, pp. 546.

21. Trismegistus H. Hermatic maxim. In: Corbin H, editors. Alone with alone. USA: Princeton University Press; 1996.

22. Wilber K. No boundary: Eastern and western approaches to personal growth. UK: Shambhala Publications; 1985.

23. Wilber K. Consciousness of transpersonal psychology. UK: Drury; 1989.

24. Wilber K. Grace and grit. UK: Shambhala Publications; 1991.

25. Wilber K. The eye of the spirit. UK: Shambhala Publications; $1998.464 \mathrm{p}$.

26. Wilber K. One taste: The Journals of Ken Wilber. UK: Shambhala Publications; 1999. 